\title{
The EVIDENT diet quality index is associated with cardiovascular risk and arterial stiffness in adults
}

\author{
Carmela Rodríguez-Martin ${ }^{1}$, Rosario Alonso-Domínguez", María C Patino-Alonso², Manuel A Gómez-Marcos³, \\ José A Maderuelo-Fernández ${ }^{1}$, Carlos Martin-Cantera ${ }^{4}$, Luis García-Ortiz ${ }^{5}$, José I. Recio-Rodríguez ${ }^{6^{*}}$ on behalf of the \\ EVIDENT group
}

\begin{abstract}
Background: We aimed to simplify information from food frequency questionnaires (FFQs) in a single parameter that allows for rapid identification of quality of patient diet and its relationship to cardiovascular risk and pulse wave velocity (PWV).

Methods: The sample from the EVIDENT study, consisting of 1553 subjects (aged 20-80 years) with no cardiovascular disease selected by random sampling among those attending primary care clinics, was used. The EVIDENT diet index (range 0-100) was calculated based on the results of a FFQ. Evaluation of dietary habits also included adherence to the Mediterranean diet (MD). Cardiovascular risk was estimated, and carotid-femoral pulse wave velocity was measured.

Results: Mean subject age was $54.9 \pm 13.8$ years, and $60.3 \%$ of subjects were female. The mean value of the EVIDENT diet index was $52.1 \pm 3.2$ points. Subjects in the third tertile (the highest score) had the greatest adherence to MD and the highest energy intake, with greater amounts of carbohydrates, protein, and fiber. The best cut-off point of the EVIDENT diet index for predicting good adherence to the MD is 52.3 ( 0.71 sensitivity, 0.61 specificity). In a multiple regression analysis, after a complete adjustment, it was estimated that for each one-point increase in the EVIDENT diet index, cardiovascular risk (CVR), blood-pressure, waist circumference, and PWV decreased by $0.14,0.43,0.24$, and 0.09 respectively $(p<0.05$, all).
\end{abstract}

Conclusions: The diet quality index developed is associated to CVR and its components, and also with arterial stiffness, as measured with PWV. This index is also a good predictor of adherence to MD.

Keywords: Food habits, Risk factors, Vascular stiffness, Diet, Mediterranean

\section{Background}

Lifestyle has been shown to be an essential determinant for the presence or absence of many cardiovascular risk factors. More specifically, wide scientific evidence exists of the relationship between dietary habits and development of cardiovascular diseases $[1,2]$.

Epidemiological studies aimed at analyzing the relationship between diet and chronic disease use different

\footnotetext{
* Correspondence: donrecio@gmail.com

${ }^{6}$ Primary Care Research Unit, The Alamedilla Health Center, Castilla and León Health Service (SACYL), Biomedical Research Institute of Salamanca (IBSAL), Spanish Network for Preventive Activities and Health Promotion (redlAPP), Department of Nursing and Physiotherapy, University of Salamanca, Avda. Comuneros $N^{\circ} 27,37003$ Salamanca, Spain

Full list of author information is available at the end of the article
}

tools to collect information on the usual diet during a given period of time. Food frequency questionnaires (FFQs) are among the most commonly used methods [3]. In Spain, the FFQ developed and used in the PREDIMED study [4] has often been used and has provided ample evidence of the benefits of the Mediterranean diet for cardiovascular health [2]. However, routine use of this FFQ in daily practice is unfeasible because of its complexity, and this questionnaire has mainly been relegated to the field of research. Recently, questionnaires that evaluate the quality of the diet have been developed, adapted to different population contexts [5-8].

The purpose of this study was to evaluate the relationship of a diet quality index derived from a food frequency 
questionnaire with the cardiovascular risk and pulse wave velocity in a sample of Spanish adults. As a secondary objective we want to evaluate how this index predicts adherence to the Mediterranean diet.

\section{Methods}

\section{Study design}

The results of this study are a subanalysis of the EVIDENT study (from the Spanish title, Estilos de vida y disfunción endotelial), which was intended to evaluate the relationship of lifestyle with circadian blood pressure pattern, arterial stiffness, and endothelial function in a cohort of adults with no cardiovascular disease. This was a cross-sectional multicenter study with the participation of six Spanish primary care centers. The protocol of the EVIDENT study [9], describing the methods used to collect information, has previously been reported.

\section{Study population}

One thousand five hundred fifty three subjects aged 20 to 80 years were selected by systematic random sampling in primary care clinics. Exclusion criteria were: coronary or cerebrovascular atherosclerotic disease, heart failure, moderate to severe chronic obstructive pulmonary disease, musculoskeletal disease that prevented walking, advanced liver, lung or kidney disease, severe mental disease, oncological disease treated and diagnosed within five years of study start, end-stage disease, and pregnancy.

\section{Variables and measurement instruments} Sociodemographic and lifestyle variables

Age, sex, occupation, smoking (non smokers, exsmokers and current smokers), and alcohol consumption were evaluated by clinical interview.

\section{Clinical history}

Cardiovascular risk factors (high blood pressure, dyslipidemia, and diabetes) and use of drugs were evaluated through the electronic medical record consultation, physical examination and clinical interview.

Risk of cardiovascular morbidity and mortality was estimated using the published risk equation (D'Agostino scale) based on the Framingham study [10]. Risk factors for morbidity and mortality used by the Framingham Risk Score include age, sex, total cholesterol, high-density lipoprotein cholesterol, and SBP as quantitative variables, and drug treatment for hypertension, smoking, and history of diabetes mellitus as dichotomous variables.

\section{Blood pressure measurement}

Systolic (SBP) and diastolic blood pressure (DBP) were measured three times in each arm, and the mean of the last two measurements in the arm with higher values was used. Measurements were performed with an OMRON model M7 blood pressure monitor (Omron Health Care, Kyoto, Japan) following the recommendations of the European Society of Hypertension [11].

\section{Anthropometric variables}

Body weight was measured twice with a certified electronic balance (Seca 770) after adequate calibration (precision $\pm 0.1 \mathrm{~kg}$ ). Readings were rounded to $100 \mathrm{~g}$. Height was measured with a stadiometer (Seca 222), recording the mean of two measurements. Body mass index (BMI) was calculated using the formula: weight in $\mathrm{kg}$ divided by height in meters squared considering obesity a BMI $\geq 30 \mathrm{Kg} / \mathrm{m}^{2}$. Waist circumference (WC) was measured with a flexible measuring tape. All anthropometric measurements were evaluated following the 2007 recommendations of the Spanish Society for the Study of Obesity [12]. All measurements were made with the patient standing, with no shoes and wearing light clothing.

\section{Analysis of pulse wave velocity (PWV)}

The Salamanca cohort (Group of participants recruited in Salamanca $N=263$ ) was measured the pulse wave velocity. Measurement was performed with the subject in supine position and using the Sphygmocor System (AtCor Medical Pty Ltd. Head Office, West Ryde, Australia), following the consensus recommendations of Van Bortel et al. [13]. Pulse wave in the carotid and femoral arteries was analyzed, and delay with regard to ECG wave was estimated. Distance measurements were taken with a measuring tape from the sternal notch to the point where sensor was located.

\section{Diet}

Dietary intake was recorded using a self-administered, semiquantitative FFQ. This questionnaire has been validated for Spain [3] and includes 137 food items frequently used by the reference population. After receiving instructions from the study staff, participants have indicated the frequency each food item had been consumed in the past year using a 9-item scale (never or almost never, 1-3 times monthly, once weekly, 2-4 times weekly, 5-6 times weekly, once daily, 2-3 times daily, 4-6 times daily, or more than 6 times daily). This questionnaire allows for estimating daily intake of energy, immediate principles, and others. The EVIDENT diet index was created based on the FFQ including the 137 foods that are collected in this questionnaire. This index scores each item depending on whether the food is considered positive, negative, or neutral for health. This consideration was based on the dietary patterns proposed in the study of Nettleton et al. [14] adapted to 
the Spanish population dietary habits. As consumption increases, score of food items considered positive increases by between 0 and 8 points, while score of those considered negative decreases by between 8 and 0 points. Neutral foods are not scored. This results in a global score which, for better understanding, has been standardized to a $0-100$ point range. Higher scores are considered representative of better quality of diet. Table 1 provides more details of calculation of this index. Adherence to Mediterranean diet (MD) was also assessed using the 14-item validated questionnaire (MEDAS) [5]. This questionnaire includes 14 items with two possible answers. Each answer considered positive for health counted as one point. The final score ranged from 0 and 14 points. Adherence to Mediterranean diet was considered good when score was 9 points or higher [5].

\section{Laboratory variables}

A blood sample was collected after a 12-h fast for measuring lipids, glucose, HbA1c and insulin. Serum total cholesterol, HDL-cholesterol and triglyceride concentrations were measured using standard automated enzymatic methods. LDL cholesterol was estimated using the Friedewald equation when the direct parameter was not available.

\section{Statistical analysis}

Results are given as mean \pm standard deviation for quantitative variables or as frequency distributions for qualitative variables. Differences in means of continuous variables between tertiles (T) of EVIDENT diet index (with $\mathrm{T} 1$ being the lowest and $\mathrm{T} 3$ the highest) were analyzed through a one-way analysis of variance (ANOVA) for independent samples, using the Fisher's Least Significant Difference $(L S D)$ method in post hoc contrasts. A multiple linear regression analysis was performed, including the EVIDENT index as independent variable and cardiovascular risk, BP, waist circumference, and PWV as dependent variables. A first unadjusted model and a second model adjusted by age and sex were performed. Finally, a third model adjusted for age, sex, smoking, energy intake, SBP, and antihypertensive, antidiabetic, and lipid-lowering treatment was used. ROC

Table 1 Composition of the EVIDENT diet index

\begin{tabular}{|c|c|c|c|}
\hline \multicolumn{4}{|l|}{ Positive food groups } \\
\hline Never or almost never & 0 points & Low-fat dairy (milk, yogurt, cheese) & Boiled or roasted potatoes \\
\hline $1-3$ times per month & 1 point & Poultry & Fruits \\
\hline Once per week & 2 points & Rabbit & Fresh fruit juice \\
\hline 2-4 times per week & 3 points & Fish & Beans, lentils, chickpeas \\
\hline 5-6 times per week & 4 points & Dark-yellow vegetables & Whole-grain bread, rice, cereal or pasta \\
\hline Once per day & 5 points & Green leafy vegetables & Olive oil \\
\hline $2-3$ times per day & 6 points & Cruciferous vegetables & Green or black tea \\
\hline 4-6 times per day & 7 points & Other vegetables & Red wine \\
\hline More than six times per day & 8 points & Gazpacho ${ }^{a}$ & Beer \\
\hline \multicolumn{4}{|l|}{ Negative food groups } \\
\hline Never or almost never & 8 points & Whole-fat dairy (milk, yogurt, cheese) & Sweet breads \\
\hline 1-3 times per month & 7 points & Ice cream & Desserts \\
\hline Once per week & 6 points & Red meat & Added sweets \\
\hline 2-4 times per week & 5 points & Processed meat & Pre-cooked meals \\
\hline 5-6 times per week & 4 points & Pizza & Sauce (ketchup, mayonnaise) \\
\hline Once per day & 3 points & Fried potatoes & Honey \\
\hline 2-3 times per day & 2 points & Salty snack foods & Jam \\
\hline 4-6 times per day & 1 point & Added fats and oils & Soda \\
\hline More than six times per day & 0 points & Butter & Bottled juices \\
\hline \multicolumn{4}{|l|}{ Neutral food groups } \\
\hline & & Semi-skimmed milk & Whole grain biscuits \\
\hline & & Eggs & Chocolate \\
\hline & & Jamón Serranob & Diet soda \\
\hline & & Refined-grain bread, rice, cereal or pasta & Other alcohol \\
\hline
\end{tabular}


Table 2 Baseline characteristics by tertiles of EVIDENT index score (Men $(n=616)$ )

\begin{tabular}{|c|c|c|c|c|}
\hline & TERTILE $1<50.12$ & TERTILE 2 (50.12 to 52.98) & TERTILE $3>52.98$ & \\
\hline & $\begin{array}{l}\text { Mean or N } \\
(\mathrm{SD} \text { or \%) }\end{array}$ & $\begin{array}{l}\text { Mean or N } \\
(\mathrm{SD} \text { or } \%)\end{array}$ & $\begin{array}{l}\text { Mean or } N \\
(\mathrm{SD} \text { or } \%)\end{array}$ & $p$ value \\
\hline Age (years) & $50.4 \pm 14.1$ & $58.5 \pm 13.1$ & $60.9 \pm 11.4$ & $<0.001$ \\
\hline Hypertension (n, \%) & $85(45.9)$ & $111(56.9)$ & $107(58.5)$ & 0.031 \\
\hline Diabetes (n, \%) & $19(10.2)$ & $35(17.9)$ & $34(18.4)$ & 0.051 \\
\hline Dyslipidemia (n, \%) & $61(34.3)$ & $92(47.2)$ & $107(58.2)$ & $<0.001$ \\
\hline Antihypertensive agents ( $n, \%)$ & $52(28.0)$ & $68(34.7)$ & $83(44.9)$ & 0.003 \\
\hline Antidiabetic agents (n, \%) & $15(8.1)$ & $23(11.7)$ & $28(15.1)$ & 0.105 \\
\hline Lipid-lowering agents (n, \%) & $26(14.0)$ & $58(29.6)$ & $63(34.1)$ & $<0.001$ \\
\hline $\mathrm{SBP}(\mathrm{mmHg})$ & $129.4 \pm 15.3$ & $132.2 \pm 15.0$ & $129.9 \pm 14.0$ & 0.155 \\
\hline $\mathrm{DBP}(\mathrm{mmHg})$ & $79.4 \pm 11.1$ & $79.3 \pm 9.4$ & $78.7 \pm 9.5$ & 0.735 \\
\hline Heart rate (bpm) & $70.5 \pm 11.7$ & $71.3 \pm 11.4$ & $68.6 \pm 12.9$ & 0.090 \\
\hline Insulinemia (mg/dL) & $8.81 \pm 6.99$ & $8.89 \pm 5.38$ & $7.49 \pm 5.19$ & 0.049 \\
\hline Glycosilated haemoglobin (\%) & $5.60 \pm 0.83$ & $5.74 \pm 0.67$ & $5.81 \pm 0.85$ & 0.039 \\
\hline Glucose (mg/dL) & $94.3 \pm 27.0$ & $97.1 \pm 19.3$ & $101.0 \pm 28.0$ & 0.037 \\
\hline Total cholesterol (mg/dL) & $203.3 \pm 40.7$ & $210.2 \pm 37.9$ & $212.3 \pm 38.0$ & 0.070 \\
\hline Triglycerides (mg/dL) & $147.0 \pm 148.8$ & $130.4 \pm 84.1$ & $142.6 \pm 158.4$ & 0.463 \\
\hline HDL-cholesterol (mg/dL) & $50.1 \pm 12.0$ & $51.7 \pm 12.0$ & $54.0 \pm 13.1$ & 0.012 \\
\hline LDL-cholesterol (mg/dL) & $131.3(45.0)$ & $133.1(32.6)$ & $134.6(32.8)$ & 0.701 \\
\hline BMI $\left(\mathrm{Kg} / \mathrm{m}^{2}\right)$ & $27.9 \pm 4.2$ & $28.1 \pm 3.5$ & $27.3 \pm 3.9$ & 0.076 \\
\hline Obesity (n, \%) & $49(26.3)$ & $56(28.6)$ & $32(17.3)$ & 0.026 \\
\hline Waist circumference $(\mathrm{cm})$ & $98.5 \pm 11.4$ & $99.7 \pm 9.4$ & $96.8 \pm 11.4$ & 0.031 \\
\hline \multicolumn{5}{|l|}{ Smoking status } \\
\hline Non smoker (n, \%) & $61(32.8)$ & $66(33.7)$ & $65(35.1)$ & \multirow[t]{3}{*}{$<0.001$} \\
\hline Exsmoker (n, \%) & $63(33.9)$ & $96(49.0)$ & $94(50.8)$ & \\
\hline Current smoker $(\mathrm{n}, \%)$ & $62(33.3)$ & $34(17.3)$ & $26(14.1)$ & \\
\hline RCV (D'Agostino) & $16.3 \pm 13.2$ & $22.6 \pm 15.5$ & $23.9 \pm 17.0$ & $<0.001$ \\
\hline $\operatorname{PWV}(\mathrm{m} / \mathrm{s})(n=263)$ & $8.13 \pm 1.95$ & $8.99 \pm 2.93$ & $7.84 \pm 2.02$ & 0.158 \\
\hline
\end{tabular}

Categorical variables are expressed as $\mathrm{n}(\%)$ and continuous variables as mean \pm standard deviation

p: statistically significant differences $(p<0.05)$

$T$ Tertile, SBP Systolic blood pressure, DBP Diastolic blood pressure, BMI Body mass index, CVR Cardiovascular risk, PWV Pulse wave velocity

curve analysis was performed to assess sensitivity, specificity, and area under the curve of the EVIDENT diet index to determine the optimum cut-off point defining good adherence to Mediterranean diet in relation to MEDAS. Statistical analysis was performed using IBM SPSS Statistics for Windows, Version 23.0. Armonk, NY: IBM Corp. A value of $p<0.05$ was considered statistically significant.

\section{Results}

A total of 1553 subjects with a mean age of $54.9 \pm 13.8$ years were enrolled into the study. Of these, $60.3 \%$ were females. The mean value of the EVIDENT diet index was $52.1 \pm 3.2$ points. The baseline characteristics by tertiles of EVIDENT index score were similar in both sexes. T1 (the tertile with the lowest score, $<50.1$ for men and $<51.4$ for women) had the lowest mean age, a smaller proportion of subjects with dyslipidemia or on lipid-lowering drugs, and a lower estimated cardiovascular risk. By contrast, T3 (the tertile with the highest score, $>52.9$ for men and $<53.8$ for women) was the oldest. Tables 2 and 3.

In both sexes, T3 had the highest energy intake, with greater amounts of carbohydrates, protein, and fiber and lower consumption of cholesterol and saturated fat-except for energy intake in men. By contrast, subjects in T1 had the greatest intake of fat (saturated fat and cholesterol) and lower consumption of fiber. Differences were found in adherence to Mediterranean diet evaluated, with the lowest and highest scores in MEDAS being found in T1 and T3 respectively $(6.4 \pm 1.7$ vs. $8.6 \pm 1.8, p<0.001$ in men; $6.8 \pm 1.9$ vs. $8.6 \pm 1.6, p<0.001$ in women). Tables 4 and 5 . 
Table 3 Baseline characteristics by tertiles of EVIDENT index score (Women $(n=937)$ )

\begin{tabular}{|c|c|c|c|c|}
\hline & TERTILE $1<51.43$ & TERTILE 2 (51.43 to 53.85) & TERTILE $3>53.85$ & \\
\hline & Mean or N (SD or \%) & Mean or N (SD or \%) & Mean or N (SD or \%) & $p$ value \\
\hline Age (years) & $48.8 \pm 14.6$ & $55.1 \pm 13.5$ & $57.6 \pm 11.5$ & $<0.001$ \\
\hline Hypertension (n, \%) & $87(29.4)$ & $112(38.5)$ & $105(35.8)$ & 0.058 \\
\hline Diabetes (n, \%) & $22(7.4)$ & $23(7.9)$ & $27(9.1)$ & 0.749 \\
\hline Dyslipidemia (n, \%) & $94(33.2)$ & $129(45.3)$ & $134(45.9)$ & 0.003 \\
\hline Antihypertensive agents ( $n, \%)$ & $61(20.6)$ & $75(25.8)$ & $78(26.3)$ & 0.206 \\
\hline Antidiabetic agents $(\mathrm{n}, \%)$ & $11(3.7)$ & $17(5.8)$ & $21(7.1)$ & 0.196 \\
\hline Lipid-lowering agents ( $n, \%)$ & $25(8.4)$ & $42(14.4)$ & $64(21.5)$ & $<0.001$ \\
\hline $\mathrm{SBP}(\mathrm{mmHg})$ & $119.8 \pm 16.9$ & $122.2 \pm 18.2$ & $120.4 \pm 17.0$ & 0.226 \\
\hline $\mathrm{DBP}(\mathrm{mmHg})$ & $74.9 \pm 11.1$ & $76.0 \pm 10.3$ & $75.7 \pm 10.3$ & 0.478 \\
\hline Heart rate (bpm) & $75.2 \pm 11.4$ & $72.1 \pm 10.5$ & $72.2 \pm 10.4$ & $<0.001$ \\
\hline Insulinemia (mg/dL) & $8.10 \pm 5.92$ & $7.44 \pm 6.02$ & $7.72 \pm 5.29$ & 0.420 \\
\hline Glycosilated haemoglobin (\%) & $5.51 \pm 0.72$ & $5.64 \pm 0.70$ & $5.63 \pm 0.72$ & 0.058 \\
\hline Glucose (mg/dL) & $90.8 \pm 22.6$ & $92.2 \pm 18.8$ & $93.0 \pm 22.4$ & 0.453 \\
\hline Total cholesterol (mg/dL) & $212.7 \pm 38.9$ & $221.3 \pm 39.4$ & $215.9 \pm 35.9$ & 0.025 \\
\hline Triglycerides (mg/dL) & $102.4 \pm 58.9$ & $110.4 \pm 90.8$ & $113.4 \pm 113.4$ & 0.329 \\
\hline HDL-cholesterol (mg/dL) & $62.7 \pm 16.6$ & $64.1 \pm 15.3$ & $63.4 \pm 14.7$ & 0.555 \\
\hline LDL-cholesterol (mg/dL) & $129.5 \pm 34.4$ & $136.5 \pm 35.8$ & $132.3 \pm 32.6$ & 0.050 \\
\hline $\mathrm{BMI}\left(\mathrm{Kg} / \mathrm{m}^{2}\right)$ & $26.2 \pm 5.1$ & $26.9 \pm 5.2$ & $26.3 \pm 4.2$ & 0.204 \\
\hline Obesity (n, \%) & $61(20.6)$ & $65(22.3)$ & $44(14.9)$ & 0.058 \\
\hline Waist circumference $(\mathrm{cm})$ & $88.7 \pm 12.8$ & $90.5 \pm 11.5$ & $89.6 \pm 11.1$ & 0.166 \\
\hline \multicolumn{5}{|l|}{ Smoking status } \\
\hline Non smoker $(\mathrm{n}, \%)$ & $146(49.5)$ & $169(58.1)$ & $186(62.6)$ & \multirow[t]{3}{*}{$<0.001$} \\
\hline Exsmoker (n, \%) & $58(19.7)$ & $67(23.0)$ & $64(21.6)$ & \\
\hline Current smoker (n, \%) & $91(30.8)$ & $55(18.9)$ & $47(15.8)$ & \\
\hline RCV (D'Agostino) & $7.1 \pm 7.6$ & $9.0 \pm 9.9$ & $8.5 \pm 7.2$ & 0.020 \\
\hline $\operatorname{PWV}(\mathrm{m} / \mathrm{s})(n=263)$ & $6.98 \pm 1.67$ & $7.46 \pm 1.73$ & $7.12 \pm 1.73$ & 0.386 \\
\hline
\end{tabular}

Categorical variables are expressed as $\mathrm{n}(\%)$ and continuous variables as mean \pm standard deviation p: statistically significant differences $(p<0.05)$

$T$ Tertile, SBP Systolic blood pressure, DBP Diastolic blood pressure, BMI Body mass index, CVR Cardiovascular risk, PWV Pulse wave velocity

In a multiple regression analysis, after a complete adjustment, it was estimated that for each one-point increase in the EVIDENT diet index, CVR, SBP, WC, and PWV decreased by $0.14,0.43,0.24$, and 0.09 respectively $(p<0.05$ for all). Table 6 .

In the ROC curve (area under the curve $0.72,95 \% \mathrm{CI}$, $0.69-0.75, p<0.001)$, the best cut-off point of the EVIDENT diet index for predicting good adherence to the Mediterranean diet was 52.3 (0.71 sensitivity and 0.61 specificity) (Fig. 1).

\section{Discussion}

The EVIDENT diet index (diet quality index derived from a FFQ) shows a close relationship to cardiovascular risk and its components, as well as pulse wave velocity, an intermediate marker in development of atherosclerosis. It has also been shown to be a very important predictor of adherence to Mediterranean diet.

Current research focuses on the study of dietary patterns, rather than analysis of given nutrients [14, 15]. Development of diet quality indices such as the EVIDENT diet index, represents a way to analyze FFQ data from a comprehensive viewpoint, using an approach different from the one most commonly applied to date. As FFQs provide a multitude of data, their routine management is difficult. There has been thus a trend to search for formulas that simplify such information [16]. Today, diet quality indices are mainly used in research, but they could be helpful in primary care clinics because they would allow for systematic, rapid, and simple understanding of the quality of patient diet and its impact on cardiovascular health. This would in turn allow for identifying, selecting, and prioritizing groups of 
Table 4 Energy intake and daily nutrients intake by tertiles of the EVIDENT diet index (Men $(n=616))$

\begin{tabular}{|c|c|c|c|c|}
\hline & TERTILE $1<50.12$ & TERTILE 2 (50.12 to 52.98) & TERTILE $3>52.98$ & \\
\hline & Mean \pm SD & Mean \pm SD & Mean \pm SD & $p$ value \\
\hline Energy intake(Kcal/day) ${ }^{a}$ & $2571.6 \pm 902.6$ & $2353.1 \pm 735.0$ & $2531.4 \pm 1051.2$ & 0.042 \\
\hline Carbohydrate $(g / \text { day })^{c}$ & $271.0 \pm 119.4$ & $249.6 \pm 93.6$ & $284.8 \pm 189.5$ & 0.046 \\
\hline Protein $(g / \text { day })^{c}$ & $103.0 \pm 32.3$ & $99.8 \pm 28.7$ & $109.3 \pm 45.4$ & 0.033 \\
\hline Total fat $(g / \text { day })^{a b}$ & $108.5 \pm 41.8$ & $92.8 \pm 32.9$ & $92.8 \pm 30.3$ & $<0.001$ \\
\hline Saturated fat $(g / \text { day })^{a b}$ & $35.7 \pm 13.0$ & $28.1 \pm 10.3$ & $25.9 \pm 9.3$ & $<0.001$ \\
\hline Fiber $(g / \text { day })^{a b c}$ & $18.9 \pm 9.1$ & $23.1 \pm 8.0$ & $33.1 \pm 28.5$ & $<0.001$ \\
\hline Cholesterol (g/day $)^{a b}$ & $512.8 \pm 222.4$ & $461.2 \pm 159.4$ & $448.2 \pm 177.8$ & 0.002 \\
\hline Carbohydrate $(\%)^{\mathrm{bc}}$ & $41.55 \pm 7.39$ & $42.00 \pm 6.99$ & $44.11 \pm 7.32$ & 0.001 \\
\hline Protein (\%) ${ }^{\mathrm{ab}}$ & $16.41 \pm 2.90$ & $17.35 \pm 3.12$ & $17.57 \pm 2.97$ & $<0.001$ \\
\hline Total fat (\%) $)^{a b c}$ & $38.08 \pm 6.11$ & $35.61 \pm 5.91$ & $33.58 \pm 6.42$ & $<0.001$ \\
\hline Alcohol (\%) & $3.96 \pm 3.96$ & $5.05 \pm 5.04$ & $4.76 \pm 4.62$ & 0.063 \\
\hline Mediterranean Diet Adherence Score ${ }^{\mathrm{abc}}$ & $6.4 \pm 1.7$ & $7.8 \pm 1.8$ & $8.6 \pm 1.8$ & $<0.001$ \\
\hline
\end{tabular}

Categorical variables are expressed as $\mathrm{n}(\%)$ and continuous variables as mean \pm standard deviation p: statistically significant differences $(p<0.05)$

Post hoc differences: ${ }^{\mathrm{a}} \mathrm{T} 1$ and $\mathrm{T} 2{ }^{\mathrm{b}}{ }^{\mathrm{T}} \mathrm{T} 1$ and $\mathrm{T} 3 ;{ }^{\mathrm{c}} \mathrm{T} 2$ and $\mathrm{T} 3$

people with poorer quality of diet. From the clinical viewpoint, FFQs allow for estimating mean daily use of energy and nutrients, but development of these quality indices also allows for comprehensive management of all information provided by these FFQs. In addition, as in the case of the EVIDENT diet index, they may be a very significant predictor of adherence to Mediterranean diet. The EVIDENT diet index simplifies the evaluation of diet quality in daily practice. This index is derived directly from the 137 -item FFQ. For the daily practice, some foods considered as neutral for the health, It may not be necessary to apply. This would have a direct effect on the evaluation time. In addition, quality indexes allow an overall view of the quality of the diet as a whole, which the FFQ does not provide.

The relationship between cardiovascular risk factors and diet quality was explored in the study conducted by Funtikova et al. [17] with a 10-year follow-up. Our study supports the conclusion that high diet quality is associated to a better profile in cardiovascular risk factors. Several studies have reported an association to blood pressure. One of the most important of these was the DASH study, which concluded that a diet rich in vegetables and fruit and low in saturated fat may decrease

Table 5 Energy intake and daily nutrients intake by tertiles of the EVIDENT diet index (Women $(n=937)$ )

\begin{tabular}{|c|c|c|c|c|}
\hline & TERTILE $1<51.43$ & TERTILE 2 (51.43 to 53.85) & TERTILE $3>53.85$ & \\
\hline & Mean \pm SD & Mean \pm SD & Mean \pm SD & $p$ value \\
\hline Energy intake(Kcal/day) ${ }^{c}$ & $2415.0 \pm 844.4$ & $2319.5 \pm 736.1$ & $2502.9 \pm 785.2$ & 0.019 \\
\hline Carbohydrate $(g / \text { day })^{\text {ac }}$ & $257.8 \pm 111.0$ & $250.7 \pm 94.4$ & $278.1 \pm 113.0$ & 0.005 \\
\hline Protein $(g / \text { day })^{b c}$ & $100.4 \pm 31.9$ & $103.0 \pm 30.1$ & $111.1 \pm 29.5$ & $<0.001$ \\
\hline Total fat $(\mathrm{g} / \text { day })^{a}$ & $105.8 \pm 39.9$ & $96.6 \pm 35.8$ & $101.0 \pm 35.8$ & 0.012 \\
\hline Saturated fat $(g / \text { day })^{a b}$ & $33.9 \pm 13.3$ & $29.0 \pm 12.4$ & $27.1 \pm 10.5$ & $<0.001$ \\
\hline Fiber $(g / d a y)^{a b c}$ & $19.7 \pm 9.1$ & $25.9 \pm 9.1$ & $33.4 \pm 12.5$ & $<0.001$ \\
\hline Cholesterol $(\mathrm{g} / \text { day })^{\mathrm{b}}$ & $467.5 \pm 175.7$ & $449.8 \pm 174.8$ & $436.0 \pm 162.2$ & 0.080 \\
\hline Carbohydrate $(\%)^{b}$ & $42.15 \pm 7.08$ & $42.97 \pm 7.18$ & $43.89 \pm 7.68$ & 0.016 \\
\hline Protein (\%) ${ }^{\mathrm{ab}}$ & $17.07 \pm 3.27$ & $18.14 \pm 3.19$ & $18.25 \pm 3.60$ & $<0.001$ \\
\hline Total fat $(\%)^{a b}$ & $39.41 \pm 6.39$ & $37.34 \pm 6.22$ & $36.32 \pm 6.43$ & $<0.001$ \\
\hline Alcohol (\%) & $1.37 \pm 2.51$ & $1.55 \pm 2.39$ & $1.54 \pm 2.82$ & 0.655 \\
\hline Mediterranean Diet Adherence Score ${ }^{\mathrm{abc}}$ & $6.8 \pm 1.9$ & $7.6 \pm 1.7$ & $8.6 \pm 1.6$ & $<0.001$ \\
\hline
\end{tabular}

Categorical variables are expressed as $\mathrm{n}(\%)$ and continuous variables as mean \pm standard deviation p: statistically significant differences $(p<0.05)$

Post hoc differences: ${ }^{\mathrm{a}} \mathrm{T} 1$ and $\mathrm{T} 2 ;{ }^{\mathrm{b}} \mathrm{T} 1$ and $\mathrm{T} 3{ }^{\circ}{ }^{\mathrm{C}} \mathrm{T} 2$ and $\mathrm{T} 3$ 
Table 6 Multiple regression analysis: Relationship between EVIDENT index with Cardiovascular risk, blood pressure, waist circumference and PW

\begin{tabular}{|c|c|c|c|c|c|c|c|c|c|c|c|c|}
\hline & \multicolumn{3}{|l|}{ CV Risk } & \multicolumn{3}{|l|}{ SBP } & \multicolumn{3}{|c|}{ Waist circumference } & \multicolumn{3}{|l|}{$\mathrm{PW}^{\mathrm{a}}$} \\
\hline & $\bar{\beta}$ & $95 \% \mathrm{Cl}$ & $p$ & $\bar{\beta}$ & $95 \% \mathrm{Cl}$ & $p$ & $\bar{\beta}$ & $95 \% \mathrm{Cl}$ & $p$ & $\bar{\beta}$ & $95 \% \mathrm{Cl}$ & $p$ \\
\hline Model 1 & 0.260 & 0.042 to 0.478 & 0.020 & -0.028 & -0.304 to 0.248 & 0.842 & -0.035 & -0.108 to 0.038 & 0.353 & -0.029 & -0.107 to 0.050 & 0.476 \\
\hline Model 2 & -0.223 & -0.377 to -0.069 & 0.005 & -0.444 & -0.708 to -0.180 & 0.001 & -0.094 & -0.170 to -0.018 & 0.015 & -0.082 & -0.147 to -0.017 & 0.014 \\
\hline Model 3 & -0.143 & -0.267 to -0.019 & 0.023 & -0.427 & -0.685 to -0.168 & 0.001 & -0.241 & -0.426 to -0.056 & 0.011 & -0.089 & -0.148 to -0.030 & 0.003 \\
\hline
\end{tabular}

CV Cardiovascular risk, SBP Systolic blood pressure, PWV Pulse wave velocity

p: statistically significant differences $(p<0.05)$

Model 1: No adjusted

Model 2: Adjusted for age, gender

Model 3: Adjusted for age, gender, smoking, energy intake, antihypertensive, antidiabetic and lipid-lowering drugs

${ }^{a}$ Model 3 (PWV). Adjusted for age, gender, smoking, energy intake, antihypertensive, antidiabetic and lipid-lowering drugs and systolic blood pressure

Independent variable: EVIDENT diet index score

blood pressure. [18]. More recently, this relationship was also analyzed in the ENCORE and OMNIHEART studies $[19,20]$ with the same results. The food groups considered more favorable for cardiovascular health in the EVIDENT diet index included skimmed milk products, vegetables, fruit, as well as other products commonly included in the Mediterranean diet such as olive oil, red wine, legumes, white meat, or fish. This group of foods represents a dietary pattern similar to that of the DASH study but with elements unique to Mediterranean countries. The relationship between diet quality and BMI was previously studied by Asghari et al. [21], who found no significant association. However, Gregory et al. [22] and Sundararajan et al. [23] reported an inverse relationship between diet quality and BMI, which was stronger in females. Our results support this relationship even after including an adjustment for confounding factors such as age, sex, use of drugs, and other lifestyles such as smoking, which did not modify the results.

However, the most important finding may be the association of the EVIDENT diet index to overall cardiovascular risk estimated using the Framingham equation. This finding agrees with the conclusions of a recent study by Sotos-Prieto et al. [24] which suggested a

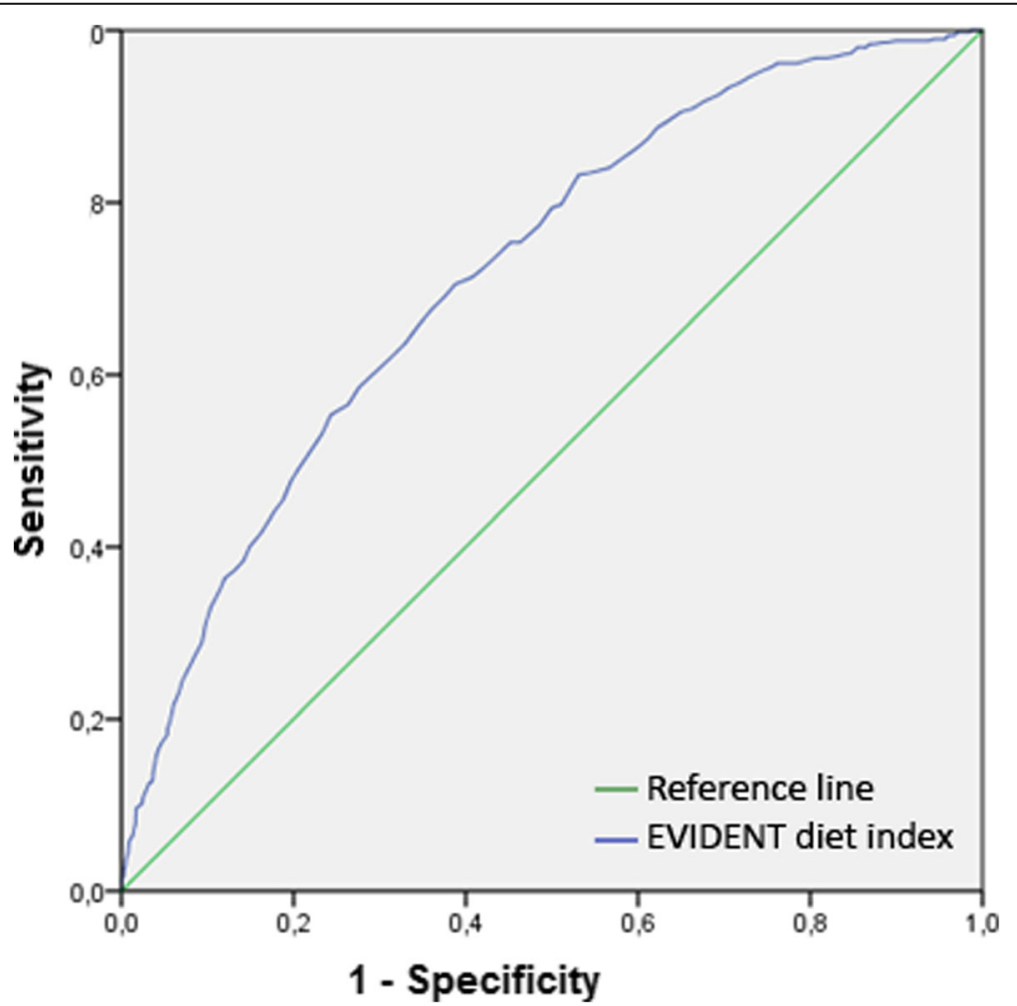

Fig. 1 ROC curves for the EVIDENT diet index scores for prediction the adherence to the Mediterranean diet. (Area under the curve $0.72,95 \% \mathrm{Cl}$, $0.69-0.75, p<0.001)$ 
relationship between diet quality and an index encompassing cardiovascular risk factors, as well as an impact on overall mortality figures [25].

Pulse wave velocity is currently considered as the gold standard in evaluation of arterial stiffness [26] and as an intermediate marker in development of cerebrovascular disease. The relationship between heart-healthy lifestyles and pulse wave velocity has been shown in several studies $[27,28]$. However, the conclusion reached in the meta-analysis conducted by Petersen et al. [29] was the need for evidence on the relationship between intake patterns and pulse wave velocity, which may be seen in our study. Higher values in the EVIDENT diet index are related to lower pulse wave velocity, even after a complete adjustment model.

Limitations of this study included that cause-andeffect relationships cannot be determined from a cross-sectional study. Future longitudinal studies may help establish causal relationships between this diet quality index and intermediate and final CVD markers. However, the study included a wide adult sample attending health care centers having heterogeneous characteristics and a wide age range, which increases validity of results. Other limitation is referred to the absence of validation and construction of the index that was based in an adapted dietary patterns proposed by other authors adapted to Spanish dietary habits.

\section{Conclusions}

The diet quality index developed from a FFQ was associated to cardiovascular risk and its components, and also to arterial stiffness, as measured with pulse wave velocity. The index is also a good predictor of adherence to Mediterranean diet in the adult population.

\section{Abbreviations \\ BMI: Body mass index; CVR: Cardiovascular risk; FFQ: Food frequency questionnaire; MD: Mediterranean diet; PWV: Pulse wave velocity; SBP: Systolic blood pressure; WC: Waist circumference}

\footnotetext{
Acknowledgements

We are grateful to all professionals and participants of the EVIDENT study. Members of the EVIDENT group:

Coordinating center (Primary Care Research Unit, La Alamedilla Health Center, Salamanca, Spain): L. García Ortiz, MA Gómez Marcos, Il Recio Rodríguez, and MC Patino Alonso. Participating centers: La Alamedilla Health Center (Castilla y León Health Service): MC Castaño Sánchez, C. Rodríguez Martin, C. Agudo Conde, E. Rodríguez Sánchez, $\amalg$ González Elena, C. Herrero Rodríguez, B. Sánchez Salgado, A. de Cabo Laso, JA Maderuelo Fernández. Passeig de Sant Joan Health Center (Catalan Health Service): C. Martin Cantera, J. Canales Reina, E. Rodrigo de Pablo, ML. Lasaosa Medina, MJ. Calvo Aponte, A. Rodríguez Franco, E. Briones Carrio, C. Martin Borras, A. Puig Ribera, R. Colominas Garrido. Poble Sec Health Center (Catalan Health Service): J. Anton Álvarez, MaT. Vidal Sarmiento, A. Viaplana Serra, S. Bermúdez Chillida, A. Tanasa. CaN'Oriac Health Center (Catalan Health Service): M. Romaguera Bosch. Sant Roc Health Center (Catalan Health Service): MM. Domingo, A. Girona, N. Curos, FJ Mezquiriz, L. Torrent. Cuenca III Health Center (Castilla-La Mancha Health Service): A. Cabrejas Sánchez, MT Pérez Rodríguez, ML. García García, JL. Bartolomé, F. Salcedo Aguilar. Casa del Barco Health Center (Castilla y León Health Service): C. Fernández Alonso, A. Gómez Arranz, E. Ibáñez Jalón, A. de la Cal de la Fuente, N. Gutiérrez, L. Muñoz, M. Menéndez, I. Repiso, R.
}

Sanz Cantalapiedra, LM. Quintero González, S. de Francisco Velasco, MA. Diez García, E. Sierra Quintana, M. Caceres. Torre Ramona Health Center (Aragon Health Service): N. González Viejo, JF. Magdalena Belio, L. Otegui llarduya, FJa. Rubio Galán, A. Melquizo Bejar, Cl. Sauras Yera, MaJ. Gil Train, M. Iribarne Ferrer, MA. Lafuente Ripolles. Primary Care Research Unit of Bizkaia (Basque Health Service-Osakidetza): G. Grandes, A. Sánchez, N. Guenaga, V. Arce, MS. Arietaleanizbeaskoa, E. Iturregui San Nicolás, RA. Martín Santidrian, A. Zuazagoitia.

\section{Funding}

This project was supported by grants funded by the Spanish Ministry of Science and Innovation (MICINN) and Carlos III Health Institute (ISCIII) and cofinanced by European Regional Development Fund (ERDF); (Red RedIAPP RD12/0005, and Health Research projects: PS09/00233, PS09/01057, PS09/ 01972, PS09/01376, PS09/0164, PS09/01458) and Regional Health Management of the Castilla and León (SAN/1778/2009). The funding body had no role in the design of the study, the collection, analysis, and interpretation of data, or the writing of the manuscript. The authors assume full responsibility for the content of the paper.

\section{Availability of data and materials}

Data are available upon reasonable request from the corresponding author or La Alamedilla-Primary Care Research Unit. E-mail: donrecio@gmail.com.

\section{Authors' contributions}

CRM and JIR interpreted results, prepared the manuscript draft and corrected the final version of the manuscript. $L G, J R, C M C$ and MAG. participated in the study design, interpretation of results and manuscript review. MCP and JAM performed all the analytical methods, interpretation of results and manuscript review. RA contributed to data collection and manuscript review. All the authors reviewed and approved the final version of the manuscript.

\section{Competing interests}

The authors declare that they have no competing interests.

\section{Consent for publication}

Not applicable.

\section{Ethics approval and consent to participate}

This study was conducted according to the guidelines laid down in the Declaration of Helsinki and all procedures involving human subjects/patients were approved by the Salamanca ethics committee. Written informed consent was obtained from all subjects/patients.

\section{Publisher's Note}

Springer Nature remains neutral with regard to jurisdictional claims in published maps and institutional affiliations.

\footnotetext{
Author details

'Primary Care Research Unit, The Alamedilla Health Center, Castilla and León Health Service (SACYL), Biomedical Research Institute of Salamanca (IBSAL), Spanish Network for Preventive Activities and Health Promotion (redIAPP), Salamanca, Spain. ${ }^{2}$ Department of statistics, University of Salamanca, Biomedical Research Institute of Salamanca (IBSAL), Spanish Network for Preventive Activities and Health Promotion (redlAPP), Salamanca, Spain. ${ }^{3}$ Primary Care Research Unit, The Alamedilla Health Center, Castilla and León Health Service (SACYL), Biomedical Research Institute of Salamanca (IBSAL), Department of medicine, University of Salamanca, Spanish Network for Preventive Activities and Health Promotion (redIAPP), Salamanca, Spain ${ }^{4}$ Passeig de Sant Joan Health Center, Catalan Health Service, Spanish Network for Preventive Activities and Health Promotion (redIAPP), Barcelona, Spain. ${ }^{5}$ Primary Care Research Unit, The Alamedilla Health Center, Castilla and León Health Service (SACYL), Biomedical Research Institute of Salamanca (IBSAL), Department of biomedical and diagnostic sciences, University of Salamanca, Spanish Network for Preventive Activities and Health Promotion (redIAPP), Salamanca, Spain. ${ }^{6}$ Primary Care Research Unit, The Alamedilla Health Center, Castilla and León Health Service (SACYL), Biomedical Research Institute of Salamanca (IBSAL), Spanish Network for Preventive Activities and Health Promotion (redlAPP), Department of Nursing and Physiotherapy, University of Salamanca, Avda. Comuneros № 27, 37003 Salamanca, Spain.
} 
Received: 14 September 2016 Accepted: 21 March 2017 Published online: 08 April 2017

\section{References}

1. Rodriguez-Monforte M, Flores-Mateo G, Sanchez E. Dietary patterns and CVD: a systematic review and meta-analysis of observational studies. $\mathrm{Br} J$ Nutr. 2015;114(9):1341-59.

2. Estruch R, Ros E, Salas-Salvado J, Covas MI, Corella D, Aros F, Gomez-Gracia E, Ruiz-Gutierrez V, Fiol M, Lapetra J, et al. Primary prevention of cardiovascular disease with a Mediterranean diet. N Engl J Med. 2013;368(14):1279-90.

3. Fernandez-Ballart JD, Pinol JL, Zazpe I, Corella D, Carrasco P, Toledo E, PerezBauer M, Martinez-Gonzalez MA, Salas-Salvado J, Martin-Moreno JM. Relative validity of a semi-quantitative food-frequency questionnaire in an elderly Mediterranean population of Spain. Br J Nutr. 2010;103(12):1808-16.

4. Martin-Moreno JM, Boyle P, Gorgojo L, Maisonneuve P, FernandezRodriguez JC, Salvini S, Willett WC. Development and validation of a food frequency questionnaire in Spain. Int J Epidemiol. 1993;22(3):512-9.

5. Schroder H, Fito M, Estruch R, Martinez-Gonzalez MA, Corella D, SalasSalvado J, Lamuela-Raventos R, Ros E, Salaverria I, Fiol M, et al. A short screener is valid for assessing Mediterranean diet adherence among older Spanish men and women. J Nutr. 2011;141(6):1140-5.

6. Verger EO, Mariotti F, Holmes BA, Paineau D, Huneau JF. Evaluation of a diet quality index based on the probability of adequate nutrient intake (PANDiet) using national French and US dietary surveys. PLoS One. 2012;7(8):e42155.

7. Vyncke K, Cruz Fernandez E, Fajo-Pascual M, Cuenca-Garcia M, De Keyzer W, Gonzalez-Gross M, Moreno LA, Beghin L, Breidenassel C, Kersting M, et al. Validation of the diet quality index for adolescents by comparison with biomarkers, nutrient and food intakes: the HELENA study. Br J Nutr. 2013;109(11):2067-78.

8. Zarrin R, Ibiebele TI, Marks GC. Development and validity assessment of a diet quality index for Australians. Asia Pac J Clin Nutr. 2013;22(2):177-87.

9. Garcia-Ortiz L, Recio-Rodriguez Jl, Martin-Cantera C, Cabrejas-Sanchez A, Gomez-Arranz A, Gonzalez-Viejo N, Iturregui-San Nicolas E, Patino-Alonso MC, Gomez-Marcos MA. Physical exercise, fitness and dietary pattern and their relationship with circadian blood pressure pattern, augmentation index and endothelial dysfunction biological markers: EVIDENT study protocol. BMC Public Health. 2010;10:233.

10. D'Agostino Sr RB, Vasan RS, Pencina MJ, Wolf PA, Cobain M, Massaro JM, Kannel WB. General cardiovascular risk profile for use in primary care: the Framingham heart study. Circulation. 2008;117(6):743-53.

11. O'Brien E, Asmar R, Beilin L, Imai Y, Mancia G, Mengden T, Myers M, Padfield P, Palatini P, Parati G, et al. Practice guidelines of the European Society of Hypertension for clinic, ambulatory and self blood pressure measurement. J Hypertens. 2005;23(4):697-701.

12. Salas-Salvado J, Rubio MA, Barbany M, Moreno B. SEEDO 2007 consensus for the evaluation of overweight and obesity and the establishment of therapeutic intervention criteria. Med Clin (Barc). 2007;128(5):184-96. quiz 181 p following 200

13. Van Bortel LM, Laurent S, Boutouyrie P, Chowienczyk P, Cruickshank JK, De Backer T, Filipovsky J, Huybrechts S, Mattace-Raso FU, Protogerou AD, et al. Expert consensus document on the measurement of aortic stiffness in daily practice using carotid-femoral pulse wave velocity. J Hypertens. 2012;30(3):445-8.

14. Nettleton JA, Schulze MB, Jiang R, Jenny NS, Burke GL, Jacobs Jr DR. A prioridefined dietary patterns and markers of cardiovascular disease risk in the multiethnic study of atherosclerosis (MESA). Am J Clin Nutr. 2008;88(1):185-94.

15. Gazan R, Bechaux C, Crepet A, Sirot V, Drouillet-Pinard P, Dubuisson C, Havard S. Dietary patterns in the French adult population: a study from the second French national cross-sectional dietary survey (INCA2). Br J Nutr. 2006-2007;2016:1-16.

16. Cleghorn CL, Harrison RA, Ransley JK, Wilkinson S, Thomas J, Cade JE. Can a dietary quality score derived from a short-form FFQ assess dietary quality in UK adult population surveys? Public Health Nutr. 2016;19(16):2915-23.

17. Funtikova A, Baena-Diez JM, Koebnick C, Gomez SF, Covas MI, Goday A, Schroder $\mathrm{H}$. Validity of a short diet-quality index to predict changes in anthropometric and cardiovascular risk factors: a simulation study. Eur J Clin Nutr. 2012;66(12):1369-71.

18. Appel LJ, Moore TJ, Obarzanek E, Vollmer WM, Svetkey LP, Sacks FM, Bray GA, Vogt TM, Cutler JA, Windhauser MM, et al. A clinical trial of the effects of dietary patterns on blood pressure. DASH collaborative research group. N Engl J Med. 1997;336(16):1117-24.

19. Hinderliter AL, Sherwood A, Craighead LW, Lin PH, Watkins L, Babyak MA, Blumenthal JA. The long-term effects of lifestyle change on blood pressure: oneyear follow-up of the ENCORE study. Am J Hypertens. 2014;27(5):734-41.

20. Molitor J, Brown IJ, Chan Q, Papathomas M, Liverani S, Molitor N, Richardson S, Van Horn L, Daviglus ML, Dyer A, et al. Blood pressure differences associated with optimal macronutrient intake trial for heart health (OMNIHEART)-like diet compared with a typical American diet. Hypertension. 2014;64(6):1198-204.

21. Asghari G, Mirmiran P, Rashidkhani B, Asghari-Jafarabadi M, Mehran M, Azizi F. The association between diet quality indices and obesity: Tehran lipid and glucose study. Arch Iran Med. 2012;15(10):599-605.

22. Gregory CO, McCullough ML, Ramirez-Zea M, Stein AD. Diet scores and cardio-metabolic risk factors among Guatemalan young adults. Br J Nutr. 2009;101(12):1805-11.

23. Sundararajan K, Campbell MK, Choi YH, Sarma S. The relationship between diet quality and adult obesity: evidence from Canada. J Am Coll Nutr. 2014;33(1):1-17.

24. Sotos-Prieto M, Bhupathiraju SN, Mattei J, Fung T, Li Y, Pan A, Willett WC, Rimm EB, Hu FB. Changes in diet quality scores and risk of cardiovascular disease among US men and women. Circulation. 2015;132(23):2212-9.

25. Kurotani K, Akter S, Kashino I, Goto A, Mizoue T, Noda M, Sasazuki S, Sawada N, Tsugane S. Quality of diet and mortality among Japanese men and women: Japan public health center based prospective study. BMJ. 2016;352:11209.

26. Mancia G, Fagard R, Narkiewicz K, Redon J, Zanchetti A, Bohm M, Christiaens T, Cifkova R, De Backer G, Dominiczak A, et al. 2013 ESH/ESC Guidelines for the management of arterial hypertension: the Task Force for the management of arterial hypertension of the European Society of Hypertension (ESH) and of the European Society of Cardiology (ESC). J Hypertens. 2013;31(7):1281-357.

27. Karimi L, Mattace-Raso FU, van Rosmalen J, van Rooij F, Hofman A, Franco $\mathrm{OH}$. Effects of combined healthy lifestyle factors on functional vascular aging: the Rotterdam study. J Hypertens. 2016;34(5):853-9.

28. Aatola H, Koivistoinen T, Hutri-Kahonen N, Juonala M, Mikkila V, Lehtimaki T, Viikari JS, Raitakari OT, Kahonen M. Lifetime fruit and vegetable consumption and arterial pulse wave velocity in adulthood: the cardiovascular risk in young Finns study. Circulation. 2010;122(24):2521-8.

29. Petersen K, Blanch N, Keogh J, Clifton P. Weight loss, dietary intake and pulse wave velocity. Pulse (Basel). 2015;3(2):134-40.

\section{Submit your next manuscript to BioMed Central and we will help you at every step:}

- We accept pre-submission inquiries

- Our selector tool helps you to find the most relevant journal

- We provide round the clock customer support

- Convenient online submission

- Thorough peer review

- Inclusion in PubMed and all major indexing services

- Maximum visibility for your research

Submit your manuscript at www.biomedcentral.com/submit
Biomed Central 